\title{
Further Experience in the Clinical Assessment of Fetal Neurobehavior
}

\author{
${ }^{1}$ Asim Kurjak, ${ }^{1}$ Ana Tikvica Luetic, ${ }^{1}$ Milan Stanojevic, ${ }^{2}$ Amira Talic, ${ }^{3}$ Ivica Zalud, ${ }^{4}$ Madeeha Al-Noobi \\ ${ }^{5}$ Sejfulah Perva, ${ }^{5}$ Mandy Abushama, ${ }^{1}$ Sanja Tomasovic, ${ }^{1}$ Sanja Zaputovic, ${ }^{6}$ Ulrich Honemeyer \\ ${ }^{1}$ Department of Obstetrics and Gynecology, Medical School, University of Zagreb, Sveti Duh Hospital Zagreb, Croatia \\ ${ }^{2}$ University of Medical Sciences and Technology, Khartoum, Sudan \\ ${ }^{3}$ Division of Maternal Fetal Medicine and Obstetrics, Gynecology Imaging Division, Department of Obstetrics and Gynecology \\ John A Burns School of Medicine, University of Hawaii, Honolulu, Hawaii, USA \\ ${ }^{4}$ Medical Services, Qatar Armed Forces, Doha, State of Qatar \\ ${ }^{5}$ Department of Obstetrics and Gynecology, Women's Hospital, Hamad Medical Corporation, Doha, State of Qatar \\ ${ }^{6}$ Welcare Hospital, Dubai, UAE
}

Correspondence: Asim Kurjak, Department of Obstetrics and Gynecology, Medical School, University of Zagreb, Sveti Duh Hospital, Zagreb, Croatia, e-mail: asim.kurjak@public.carnet.hr

\begin{abstract}
Recent development of three-dimensional (3D) and four-dimensional ultrasound (4D) provided us with new possibilities to study fetal movements and behavior. Many studies have been conducted in order to provide information on specific movement pattern appearance in normal and high-risk fetus. This was the base for multicenter study on use of new scoring system for fetal neurobehavior which purpose is to recognize fetuses with increased risk for poor neurological outcome. The purpose of this paper is to give brief review on the use of $3 \mathrm{D}$ and $4 \mathrm{D}$ ultrasound in the assessment of fetal behavior.

Objectives

- Define possibilities to study fetal movements and behavior by 3D and 4D ultrasound

- Decribe new scoring system for neurobehavior in fetuses with increased risk for poor neurological outcome

- Summarize behavioral perinatology research and potential clinical applications

Keywords: Fetal neurobehavior, Three-dimensional/Four-dimensional sonography.
\end{abstract}

\section{INTRODUCTION}

Fetal behavior, defined as any observable action or reaction to an external stimulus by the fetus, reflects the activity of the fetal central nervous system. Insight in fetal behavior is crucial for the understanding of normal fetal well-being and in determining whether a fetus may be compromised. Since recently, maternal registration of fetal movements and obstetrician auscultation of fetal heartbeats were the only methods for judgement about fetal state in utero. This was changed with the development of real time two-dimensional (2D) ultrasound that enabled the direct visualization of fetal anatomy and achieved in observing fetal activity. This great accomplishement investigators used as a starting point for analysis of fetal behavior in comparison with morphological studies which led to the conclusion that fetal behavioral patterns directly reflect developmental and maturational processes of fetal central nervous system. ${ }^{1,2}$ Therefore, it was suggested that the assessment of fetal behavior in different periods of gestation may provide the possibility to distinct between normal and abnormal brain development, as well as early diagnose of various structural or functional abnormalities. ${ }^{1}$ However, 2D ultrasound with poor quality of image, especially in the beginning, was considered somewhat subjective method because information needs observer interpretation. The latest development of threedimensional (3D) and four-dimensional (4D) sonography and their implementation into the clinical practice enable precise study of fetal and even embryonic activity. The use of these new technologies has shown that fetal activity appears as early as the late embryonic period, which is far earlier than a mother can sense it, what could be potentionally used in early embryonic neurobehavior assessment with great implications in termination of pregnancy in a case of 
an abnormal finding. Since now the investigation of fetal neurobehavior seems inconceivable without the use of ultrasound fetal behavior can be defined as any fetal activity observed or recorded with ultrasonographic equipment.

\section{FETAL MOTILITY AND FOUR-DIMENSIONAL ULTRASOUND}

Although 2D sonography enhanced our understanding of fetal neuromuscular development, the real breakthrough in studying fetal neurobehavior was achieved by 3D/4D ultrasound. This technique has important advantages, such as the ability to study fetal activity in the surface-rendered mode, it is particularly superior for fast fetal movements and it is better in visualization of the fetal face. ${ }^{3}$ Fetal movements such as yawning, swallowing and eyelid movements cannot be displayed simultaneously, whilst, with 4D sonography, the simultaneous facial movements can be clearly depicted. ${ }^{4}$ Its additional advantage in comparison with 2D ultrasound is the ability to visualize the whole fetus continuously. The key benefit of 4D ultrasound lies in providing real-time 3D images of embryonic or fetal movements, previously limited by technological possibilities. The introduction of high-frequency transvaginal tranducers has resulted in remarkable progress in ultrasonographic visualization of early embryos and fetuses and the development of sonoembryology. For the first-time parallel analyses of structural and functional parameters in the first 12 weeks of gestation become possible.

Three-dimensional ultrasound has been extensively used for more than ten years with development of several different kinds of modes that have been created for different purposes. They include multiplanar imaging, volume rendering, surface rendering, 3D color Doppler, and 3D volumetry, cine-loop animation, postprocessing and cutting. However, the 3D image freezes the object and therefore does not provide information on movements or any information about the dynamic changes of the object of interest. A technique was needed that would enable $3 \mathrm{D}$ imaging to be preformed in a real-time mode. This technique can be called live 3D ultrasound (3D-US) or 4D ultrasound (4D-US), as coined by a manufacturer, because time becomes a parameter within the 3D imaging sequence. Human eyes are known to be able to differentiate between images up to a frequency of about 12 images per second, consequently production of an appropriate frame rate with specially designed probes and a fast computer rendering device is required. At the moment 4D-US scanning is not real-time and available machines can reach up to about 20 images per second, depending on volume size, resolution and the mechanics of the probe. Nevertheless, even at these relatively slow frame rates the ability to study fetal activity is strikingly good enabling the continuous monitoring of the fetal face and other surface features of the fetus such as fetal extremities. This was the beginning of investigation of the relatively unexplored area of fetal behavior as a possible measure of neurological maturation.

In the early second trimester 4D-US provides simultaneous visualization of all four extremities and enables confident recognition of isolated arm movements and their direction. Because of the limitations of 2D-US only five types of isolated hand movements can be described. They include: hand to head, hand to trunk, hand to foot, hand to fluid and hand to the uterine wall. If one performs 4D-US hand to head movement can be differentiated into seven subgroups: hand to head, hand to mouth, hand near mouth, hand to face, hand near face, hand to eye and hand to ear.

With 4D-US, it is now feasible to study a full range of facial expressions including smiling, crying, scowling and eyelid movements. ${ }^{4,5}$ The observation of facial expression may be of scientific and diagnostic value and such scientific approach opens an entirely new field. Recently, multicentric studies of fetal brain function have been carried out, ${ }^{6-8}$ the aim of which was to establish the standards of fetal peripheral and body movements, and facial expressions as additional diagnostic criteria for prenatal brain impairment. It is our belief that 4D ultrasound will have its place in everyday obstetric practice, combining patient acceptance and sensitivity of diagnosis.

\section{CLASSIFICATION OF MOVEMENT PATTERNS}

Based on the first analysis of fetal movements by 2D ultrasonography, de Vries classified movements into different patterns as following: ${ }^{9,10}$

1. Sideways bending: Between 7 and 8 weeks postmenstrual age, slow and small displacements at one or two poles of the fetus occurs, lasting from half a second to two seconds, which usually occurs as a single event and disappears through gestation.

2. Startle: A startle consists of a rapid phase contraction of all limb muscles. It often spreads to the trunk and neck. It occurs frequently in the first trimester from 8 weeks on. 
3. General movements: These movements are complex movements including neck, trunk and limbs that are applicable if the whole body is moved but no distinctive patterning or sequencing of the body parts can be recognized. They wax and wane in intensity, force, and speed, and they have gradual beginning and end. These movements are performed from 8 weeks and on.

4. Hiccup: A hiccup consists of a jerky contraction of the diaphragm. Hiccups appear from 9 weeks and on, often in series, for up to several minutes, and isolated arm and leg movements can be observed.

5. Breathing: Fetal breathing movements are usually paradoxical in a way that every contraction of the diaphragm (which after birth leads to an inspiration) causes an inward movement of the torax. The onset of fetal breathing is around the 10th week of gestation. Early in gestation, they are present continually and are associated with activity in the postural muscles of the neck and limbs.

6. Isolated arm or leg movement: These movements appear around 10th week of gestation and they vary in speed and amplitude. They involve extension, flexion, external and internal rotation, or abduction and adduction of an extremity, without movements in other body parts.

7. Twitches: Twitches are quick extensions or flexions of a limb or the neck. They are not generalized or repetitive.

8. Clonic movements: These are repetitive movements of one or more limbs at a rate of about three per second.

9. Isolated retroflexion of the head: Retroflexions of the head are usually carried out slowly, but they can also be fast and jerky. These movements can be seen around 10th week and on.

10. Isolated rotation of the head: Rotation of the head is carried out at a slow velocity and only exceptionally at a higher speed. The head may turn from a midline position to one side and back.

11. Isolated anteflexion of the head: Anteflexion of the head is carried out only at a slow velocity. The displacement of the head is small. The duration is about $1 \mathrm{~s}$.

12. Jaw movements: The onset of irregular jaw opening is at 11th week. The opening may be either slow or quick. The duration of opening varies from less than $1 \mathrm{~s}$ to $5 \mathrm{~s}$.

13. Sucking and swallowing: At 13 weeks rhythmical sucking movements, often followed by swallowing, occur in bursts indicating that the fetus is drinking amniotic fluid.

14. Hand-head contact: In this pattern of movement, the hand slowly touches the face, and the fingers frequently extend and flex. These movements appear from 10th week and on and at first they usually represent an accidental contact of a hand with the face or mouth. Subgroups of these movements are: (a) hand to head - when hand movement ends at contact of fingers with the parieto-occipitotemporal region of the head; (b) hand to mouth - when hand movement ends at contact of thumb or finger with the mouth, lips or the immediate oral region; (c) hand near mouth - when movement ends with fingers in fluid between nose and shoulders/nipples or between both shoulders. Hands must be below eyes and within the area defined by the ears, less than a hand away from the mouth; (d) hand to face - when movement ends with hand in contact with the face (cheeks, chin, forehead); (e) hand near face - when movement ends with finger in fluid in front of the face but not in mouth region; (f) hand to eye - when movement ends with hand or palm or fingers in the eye region; (g) hand to ear - when movement ends at hand contact with the ear.

15. Stretch: A stretch is a complex motor pattern, which is always carried out at a slow speed and consists of the following components: forceful extension of the back, retroflexion of head, and external rotation and elevation of the arms. It retaines an identical movement form into adult life.

16. Yawn: This movement is similar to the yawn observed after birth: prolonged wide opening of the jaws followed by quick closure, often with retroflexion of the head and sometimes elevation of the arms. This movement pattern is nonrepetitive and it appears around 11th week. The anatomical criterion for fetal yawning is retraction of the tongue, whereas yawning in adults is characterized by an extended tongue.

17. Rotation of the fetus: Rotation of the fetus occurs around the sagittal or transverse axis. A complete change in position around the transverse axis, usually 
with a backwards somersault, is achieved by a complex general movement, including alternating leg movements, which resemble neonatal stepping.

\section{ONSET OF SPECIFIC FETAL BEHAVIORAL PATTERNS ASSESSED BY 3D/4D}

\section{The First Trimester}

Beside 3D-US that allows precise morphological examinations of conceptus in the first trimester, 4D-US adds quantitative assessment of fetal motility that can be performed almost equally precisely as by conventional 2DUS even at the very early period of gestation. ${ }^{11}$ Our own study showed that both 2D and 4D sonography can be used to assess fetal movements in the first trimester. ${ }^{12}$ Moreover, 4D-US offers an advantage of simultaneous visualization of the whole body.

The early embryonic development is characterized by the immobility of an embryo. Most types of movement pattern emerge between 7 and 15 weeks of gestation and from the 15th week onwards, distinct patterns can be seen. ${ }^{12}$ One of the first studies from Zagreb group on fetal behavior assessed by $4 \mathrm{D}$ sonography showed that three types of movements can be visualized in the first trimester: gross body movements between seven and eight weeks, limb movements after 10 weeks, and complex movements after 11 weeks of gestation ${ }^{8,13}$ (Figure 1).

An alteration from the given pattern of motoric development should be considered as an indication for further

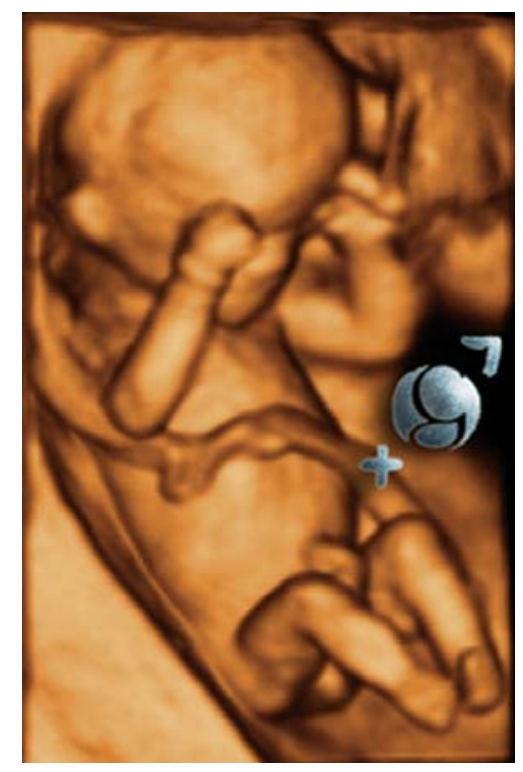

Figure 1: Three-dimensional (3D) ultrasound assessment of fetus in the first trimester showing complex movements of body and limbs investigation. ${ }^{13}$ In another study by the same group body and limb movements were visualized by 4D sonography a week earlier than by 2D. ${ }^{14,15}$

In a little while, these first simple movements are replaced by different general movements (GMs). ${ }^{13}$ At first, GMs are slow and of limited amplitude and from 10 to 12 weeks, GMs become more forceful but are smooth in appearance and of large amplitude. We can suppose that the generating neural network responsible for GMs is located in the brainstem and spinal cord, higher structures of the brain playing more subtle role in modulating quality and, perhaps, time patterning of the different movement patterns. ${ }^{16}$ Isolated limb movements emerge almost simultaneously with the general movements and they could be seen from 8 th to 9 th weeks of gestation by $4 \mathrm{D}-\mathrm{US}{ }^{16}$ Organization of the appearance of the movement pattern occurs with the increasing frequency. It seems that fetal arms explore the surrounding environment and cross the midline, while the palmar surface is oriented towards the uterine wall. The fetal legs are extended to the uterine wall. From the 10th week onwards, the number and frequency of fetal movements increase and the repertoire of movements begins to expand. Breathing movements appear between 10.5 and 12 weeks and consist namely of the opening of the jaw, bending forward of the head and complex stretch movements are added to the repertoire. ${ }^{17}$

To determine the accuracy of 4D sonography in the assessment of embryonic and early fetal motor activity in the first trimester of normal pregnancy the Zagreb group conducted a study with fifty pregnant women and performed 2D and 4D recordings. Several movement patterns, such as sideway bending, hiccup, fetal breathing movements and facial movements could not be observed by 4D-US imaging technique, although they were clearly visible by $2 \mathrm{D}-\mathrm{US}$. The authors concluded that at the time, both 2D and 4D methods were required for the assessment of early fetal motor development and motor behavior. It was reasonable to expect that such technological improvement may provide some new information about the intrauterine motor activity and facilitate the prenatal detection of some neurological disorders. ${ }^{17}$

Detailed observation of fetal hand and finger positioning by $3 \mathrm{D} / 4 \mathrm{D}$ ultrasound revealed that at the beginning of the 10th week, fetal hands are located in front of the chest without movements of wrists or fingers. Active arm movements can be visualized from the middle of 10th week of gestation with changes in finger positioning from 11th week. ${ }^{18}$ 
In the first trimester one could notice a tendency towards an increased frequency of fetal movement patterns with increasing gestational age. Only the startle movement pattern seemed to occur stagnantly during the early gestation. ${ }^{19}$

\section{The Second Trimester}

Only a few studies are available on fetal movement patterns during the second trimester. ${ }^{15,35,36-40}$ In this period of gestation the incidence of body movements increases considerably with longer periods of quiescence. The most active fetal behavioral pattern is arm movement, whereas the least active is mouth movement. Each fetal movement was shown to be synchronized and harmonized in this period of pregnancy. ${ }^{20}$ Important movements that are most developed in the second trimester are eye movements with isolated eye blinking patterns seen as consolidate movements from the 24th to 26th week of gestation, while facial grimaces are seen as sporadic movements with a limited frequency. ${ }^{21}$ From a developmental point of view, one could say that in the second trimester the development continues, but there are no new movements appearing for the first-time. ${ }^{22}$

Using 4D sonography, the Zagreb group have found that from 13 gestational weeks onwards, a "goal orientation"' of hand movements appears and a target point can be recognized for each hand movement. ${ }^{23,} 24$ All subtypes of hand to head movement could be seen from 13 weeks of gestation, with fluctuating incidence (Figure 2).

Among facial expressions, two types could be easily differentiated: smiling and scowling. The authors concluded

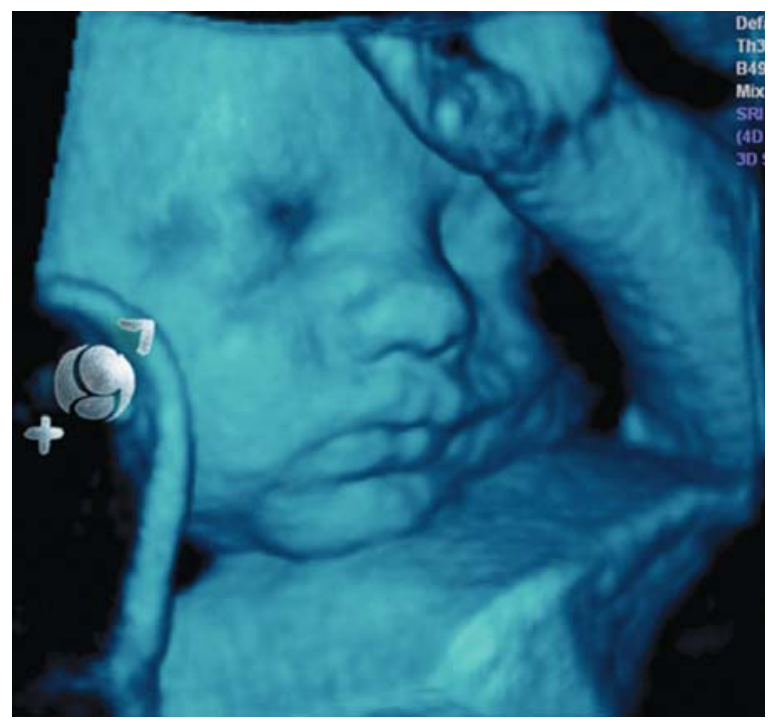

Figure 2: Example of three-dimensional (3D) ultrasound assessment of the fetal face and isolated hand movement in the second trimester that 4D-US is superior over 2D real-time ultrasound for the qualitative, but inferior for quantitative analysis of hand movements. Thus 4D-US makes it possible to determine exactly the direction of the fetal hand, but the exact number of each type of hand movements could not still be determined. Two-dimensional sonography easily recognizes hand movements associated with body movements, but there are problems in the recognition and differentiation of isolated hand movements and hand movements associated with leg movements. In this situation 4D-US is the method of choice for the reliable recognition of the isolated hand movements. Additionally, 4D sonography provides surface rendered images of the fetal head and visualization of hand movements in three-dimensions that allows further differentiation of hand to head movements. ${ }^{23,24}$

Kurjak et al. reported the first study with the 4D-US techniques used for obtaining longitudinal standard parameters of fetal neurological development in all trimesters of a normal pregnancy. ${ }^{25}$ Valid reference ranges appropriate for gestational ages are essential for comparisons with previous measurements of the same patients and among patients as well. The authors found a tendency towards an increase in the frequency of fetal movement patterns at the beginning of the 2nd trimester. All types of facial expressions display a peak frequency at the end of the 2nd trimester, except in isolated eye blinking which increases at the beginning of 24th week. This longitudinal study establishes reference ranges with gestational age for suggestible used fetal neurobehavioral development parameters in respected number of normal singleton pregnancies. Results from Yigiter and Kavak are similar as they found a significant correlation between all head movements and hand to body contact patterns during the 2nd and the 3rd trimesters except for head anteflexion, which did not show a significant change during the second-half of p regnancy. ${ }^{19}$ It has also been suggested that there is a tendency towards decreased frequency of observed facial expressions and movement patterns with increasing gestational age. ${ }^{25}$ All types of facial expressions display a peak frequency at the end of the 2nd trimester, except in isolated eye blinking which increases at the beginning of 24 th week. ${ }^{25}$

\section{The Third Trimester}

During this period of pregnancy, motor behavior becomes increasingly frequent and variable with an obvious developmental improvement in orienting responses. Prechtl 
showed that the development was intraindividually characteristic and consistent, but interindividually variable. ${ }^{26}$ In short, a rich variety of fetal and premature movements has been described and it has been shown that the repertoire of fetal movements consists exclusively of motor patterns which can also be observed postnatally and that there is a high degree of continuity of behavior before and after birth. However, the newborn's behavioral repertoire rapidly expands with patterns never observed in the fetus, such as the Moro response.

The concept of behavioral states has been used as a descriptive categorization of behavior in the third trimester as an explanatory concept in which states are considered to reflect particular modes of nervous activity that modify the responsiveness of the infant. ${ }^{27}$ These states consist of fetal heart rate pattern, and eye and body movements. ${ }^{27}$ The association of these movements increases steadily and, in the last weeks of pregnancy, authors stated that fetal behavior can almost completely be described in terms of behavioral states, which are stable over time and recur repeatedly, not only in the same infant, but also in similar forms in all infants. $^{27,28}$

By term, number of generalized movements reduces as a result of cerebral maturation processes. ${ }^{29}$ Simultaneously with this decrease, an increase in the facial movements, including opening/closing of the jaw, swallowing and chewing can be observed. ${ }^{29}$ However, not only the changes in the quantity of movements, but also in their quality are shown to be the result of maturational processes.

The incorporation of 3D-US technology into clinical practice has resulted in remarkable progress in visualization and anatomic examination of the fetal face. 4D-US, in turn, provided for the first-time an opportunity to evaluate subtle fetal facial expressions, which can be used to understand fetal behavior ${ }^{30}$ (Figure 3).

Because of its curvature and small anatomic details, the fetal face can be visualized and analyzed only to a limited extent with 2D-US, but 3D-US allows spatial reconstruction of the fetal face and simultaneous visualization of all facial structures such as the fetal nose, eyebrows, mouth, and eyelids. This technique does not replace conventional realtime 2D-US imaging, but rather supplements it. 3D-US requires an investment of additional time in each case; therefore, it is predominately used, presently in conjunction with 2D-US, as a problem-solving tool.

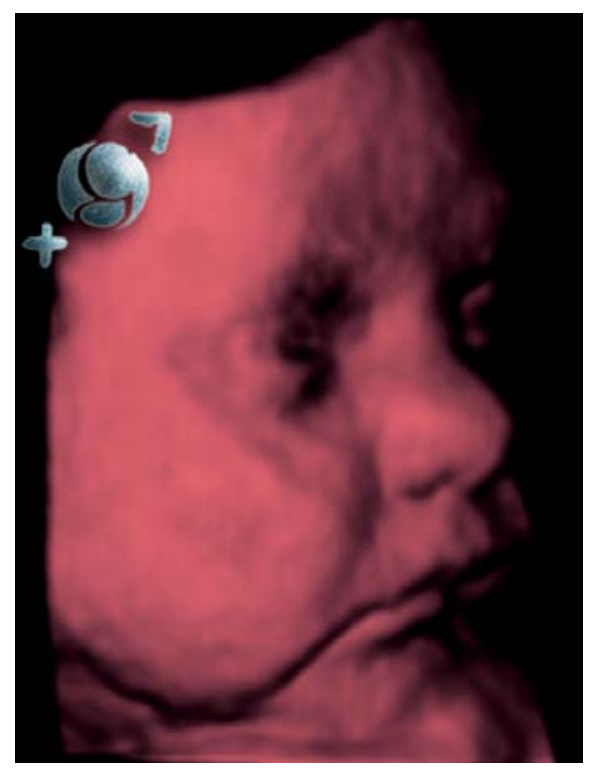

Figure 3: Example of three-dimensional (3D) ultrasound assessment of the fetal face in the third trimester which provides the possibility to study a full range of facial expressions including smiling, crying, scowling and eyelid movements

Although facial movements, which are controlled by $\mathrm{V}$ and VII cranial nerves, appear around 10 and 11 weeks, the exact onset of facial expressions has not been determined and it is still unclear whether their appearance is gestational age related. ${ }^{30}$ The possibility of studying such subtle movements might open a new area of investigation.

Zagreb group undertook the study to show the ability of 4D sonography to depict different facial expressions and grimacing which might represent fetal awareness. ${ }^{31}$ This was based on the consideration that "the face predicts the brain" because of the same embryologic origin for many facial and encephalic structures. ${ }^{32}$ A tendency towards increased frequency of observed facial expressions with increasing gestational age was noted, but the difference between second and third trimester fetuses was not significant due to the low frequency of movements. As at that time the images were only near real-time, they were only able to study the quantity and not the quality of facial movement patterns with the possibility that some very subtle facial movements may have been missed.

Recently, Yan and his group found that mouthing was the most active facial expression from 28 to 34 weeks. $^{33}$ However, the frequency of blinking was lower compared to other studies maybe due to the differences in the characteristics of the samples recruited and differences in interpreting the definition of each facial expression. ${ }^{23,31}$ 


\section{NEW SCORING SYSTEM FOR FETAL NEUROBEHAVIOR ASSESSED BY 3D AND 4D SONOGRAPHY}

In the recent study, the Zagreb group attempted to produce a new scoring system for fetal neurobehavior based on prenatal assessment by 3D/4D sonography. ${ }^{34}$ That scoring system is a combination of prenatally visualized parameters by 4D-US from other previously used tests as fetal GM assessment and postnatal ATNAT. ${ }^{35,36}$ The parameters were chosen basing on developmental approach to the neurological assessment and on the theory of central pattern generators of GM emergence and were the product of multicentric studies conducted during several years ${ }^{24,25}$ (Table 1).
The authors developed a three-point scale for isolated head anteflexion, isolated hand, leg, hand to face and finger movements, while for the assessment of cranial sutures, isolated eye blinking, facial alterations and mouth opening two-point scale was applied. The distinction between scores 0 and 2 is evident, whereas uncertainty may exist with regards to the assignation of a score of 1 , the latter indicating an abnormal result of moderate degree. The precise description of the moderate abnormal performance is included for each item in the record form.

To produce the new scoring test the Zagreb group identified severely brain damaged infants and those with optimal neurological findings by comparing fetal with

Table 1: Neurological scoring test for fetus

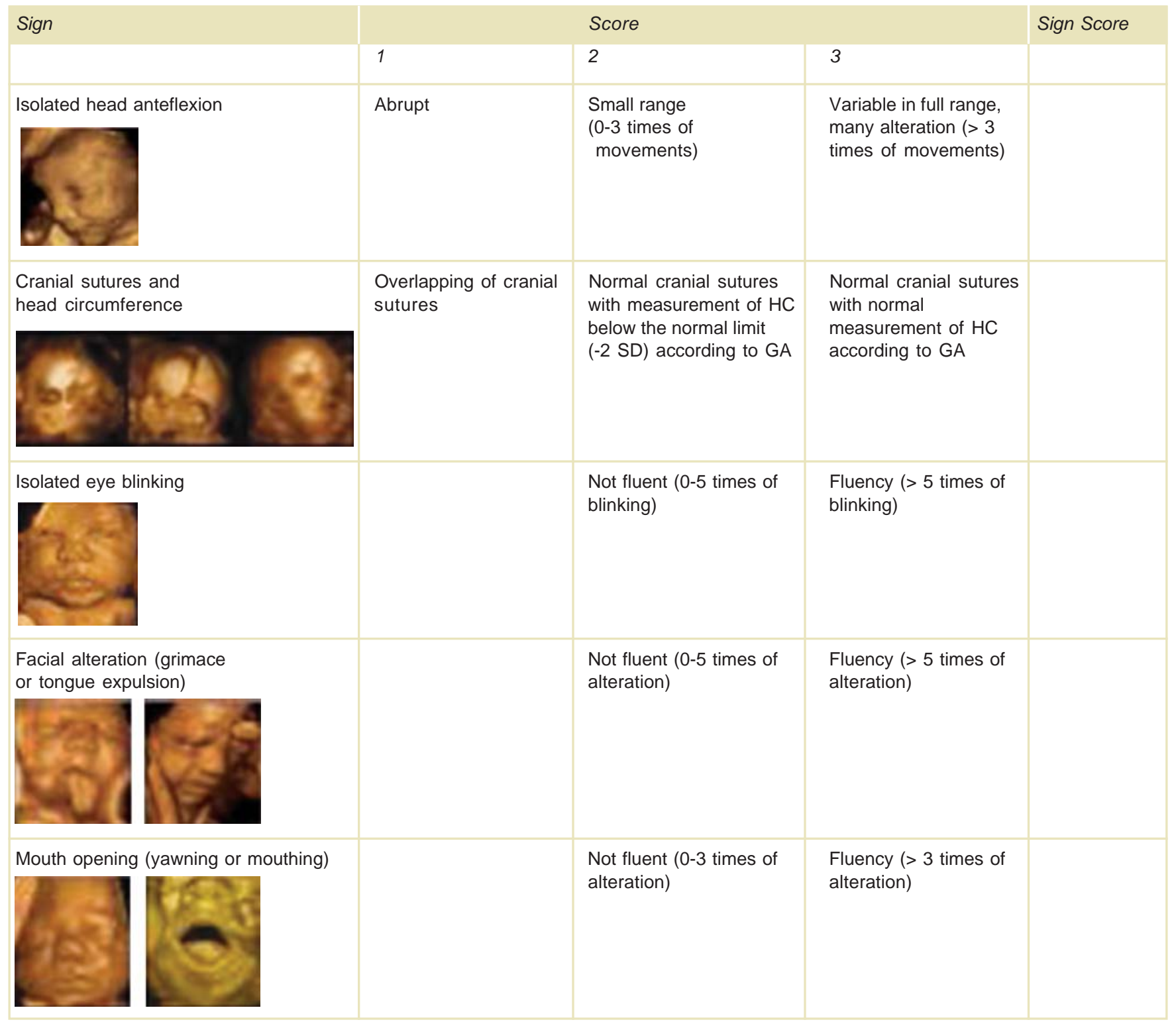

Contd... 
Contd...

\begin{tabular}{|c|c|c|c|c|}
\hline \multirow[t]{2}{*}{ Sign } & \multicolumn{3}{|c|}{ Score } & \multirow[t]{2}{*}{ Sign Score } \\
\hline & 1 & 2 & 3 & \\
\hline Isolated hand movement & Cramped & Poor repertoire & Variable and complex & \\
\hline Isolated leg movement & Cramped & Poor repertoire & Variable and complex & \\
\hline Hand to face movements & Abrupt & $\begin{array}{l}\text { Small range }(0-5 \text { times of } \\
\text { movement) }\end{array}$ & $\begin{array}{l}\text { Variable in full range, } \\
\text { many alternation }(<6 \\
\text { times of movements })\end{array}$ & \\
\hline Fingers movements & $\begin{array}{l}\text { Unilateral or bilateral } \\
\text { clenched fist, } \\
\text { (neurological thumb) }\end{array}$ & $\begin{array}{l}\text { Cramped invariable } \\
\text { finger movements }\end{array}$ & $\begin{array}{l}\text { Smooth and complex, } \\
\text { variable finger } \\
\text { movements }\end{array}$ & \\
\hline \multirow[t]{2}{*}{ Gestalt perception of GMs } & Definitely abnormal & Borderline & Normal & \\
\hline & & & Total score & \\
\hline
\end{tabular}

neonatal findings. In the group of 100 low-risk pregnancies they retrospectively applied new scoring system. After delivery, postnatal neurological assessment (ATNAT) was performed, ${ }^{37}$ and all neonates assessed as normal reached a score between 14 and 20, which was assumed to be a score of optimal neurological development. New scoring system was applied in the group of 120 high-risk pregnancies in which, based on postnatal neurological findings, three subgroups of newborns were found: normal, mildly or moderately abnormal and abnormal. Based on this, a neurological scoring system has been proposed. All normal fetuses reached a score in the range from 14 to 20. Ten fetuses who were postnatally described as mildly or moderately abnormal achieved prenatal score of 5 to 13, while another ten fetuses postnatally assigned as neurologically abnormal had a prenatal score from 0 to 5 . Among this group four had alobar holoprosencephaly, one had severe hypertensive hydrocephaly, one had tanatophoric dysplasia and four fetuses had multiple malformations.

That was a preliminary study that has already been continued in several collaborative centers. Future database formed using this new score for fetal neurological assessment will help in distinguishing fetal neurobehavioral impairements due to the early brain damage occurring in utero. It is hoped that the study of a large population will hopefully validate the value of the new test as a predictive marker for fetal neurodevelopmental outcome in both low risk and high-risk populations. 


\section{MULTICENTRIC STUDY}

In our recent paper ${ }^{38}$ the potential of the test was investigated at four university departments after proper training has been done by the authors of the test. We are reporting here on the preliminary results obtained in the high risk group of patients, trying to distinguish normal fetal brain and neurodevelopmental alterations due to the early brain impairment occurring in utero.

The study participants were singleton pregnant women in the second and the third trimester of pregnancy (between 20 and 38 weeks of gestation), recruited in out- and inpatient clinics of University Departments of Obstetrics and Gynecology from four centers: General Hospital "Sveti Duh”, Zagreb, Croatia, Marmara University Hospital, Istanbul, Turkey, University Hospital Bucharest, Romania, and Hamad Medical Center, Doha, Qatar.

This was a multicenter, prospective cohort study; 288 pregnant women meeting the inclusion criteria given in the Table 2 were found eligible to be included in the study. Distribution of study participants throughout four centers is presented in the Table 2 .

The study was conducted after the approvals of local ethics committees of four above mentioned institutions. Each participant signed informed consent form.

Fetal behavior was assessed by four-dimensional ultrasound (4D-US). All 4D-US examinations were performed by experienced operators using either the Voluson 730 Expert 11 (General Electric, USA) or Sonoline Antares (Siemens AG, Issaquah, USA) with transabdominal $5 \mathrm{MHz}$ transducer. Methods of assessment have been described elsewhere.

The KANET was used to assess fetal neurobehavior. The test has already been described elsewhere, but in this study we used a slightly modified version with the same

Table 2: Inclusion criteria

\begin{tabular}{|l|l|}
\hline Family history & Previous child with cerebral palsy \\
\hline Maternal condition & $\begin{array}{l}\text { Diabetes mellitus type I and II, thyroid } \\
\text { disease, pre-existent hypertension, drug } \\
\text { abuse, thrombophilia, anemia, epilepsy }\end{array}$ \\
\hline $\begin{array}{l}\text { Pregnancy related } \\
\text { disorders }\end{array}$ & $\begin{array}{l}\text { Gestational diabetes, Rh immunization, } \\
\text { threatened preterm labor, pre-eclampsia, } \\
\text { intrauterine infections, viral illness, } \\
\text { cholestasis }\end{array}$ \\
\hline Fetal condition & $\begin{array}{l}\text { Structural and chromosomal abnormalities, } \\
\text { polyhydramnion, intrauterine growth } \\
\text { restriction, pathological findings in electrical } \\
\text { fetal heart monitoring or Doppler findings }\end{array}$ \\
\hline
\end{tabular}

Table 3: Allocation of fetuses according to Kurjak's antenatal neurological screening test

\begin{tabular}{|ll|}
\hline Total score & Interpretation \\
\hline $0-5$ & Abnormal \\
\hline $6-13$ & Borderline \\
\hline $14-19$ & Normal \\
\hline
\end{tabular}

descriptions of the parameters and the different scoring scale which was for all parameters from 0 to 2 , while in the originally published scoring test the scale was from 1 to 3 . The used KANET form is illustrated on the Table 1. Table 3 was constructed arbitrary, representing allocation of fetuses into three separate groups after KANET assessment: 0 to 5 points were considered abnormal; 5 to 13 borderline; $\geq 14$ normal.

All neonates underwent postnatal neurological screening assessment according to Amiel Tison (ATNAT) at the postnatal age of one to three days. After the assessment infants were assigned as normal, borderline or abnormal. Infants from the borderline and abnormal group were assigned to the high-risk group for development of neurological impairment. In this group of infants, for the purpose of this preliminary study, Prechtl's general movements were evaluated at the premature (28 to 36 postmenstrual weeks) and term (37 to 46 postmenstrual weeks) age. It is planned to repeat the GM assessment at the writhing age (46 to 52 postmenstrual weeks) and fidgety age (54 to 60 postmenstrual weeks). After any assessment of GM infant was classified to one of the groups according to Hadders Algra: normal optimal, normal suboptimal, abnormal, and definitely abnormal. To simplify the analysis the infants who were normal optimal and normal suboptimal were considered as "normal" while the infants who were abnormal were considered as borderline, while those who were definitely abnormal were considered as abnormal.

All infants have been planed to be assessed by ATNAT screening test at 1, 3, 6, 9, 12, 18 months of corrected age, while final assessment was planned to be at the corrected age of 24 months. All infants who needed additional assessments like neuroimaging, electrophysiological, ophthalmologic, orthopedic or any other examination were supposed to get it according to the local availability. It was intended to make the final diagnosis of disabling or nondisabling cerebral palsy at the corrected age of 24 months on the basis of child's ability to walk. Figure 4 is presenting postnatal assessment Flow Chart. 


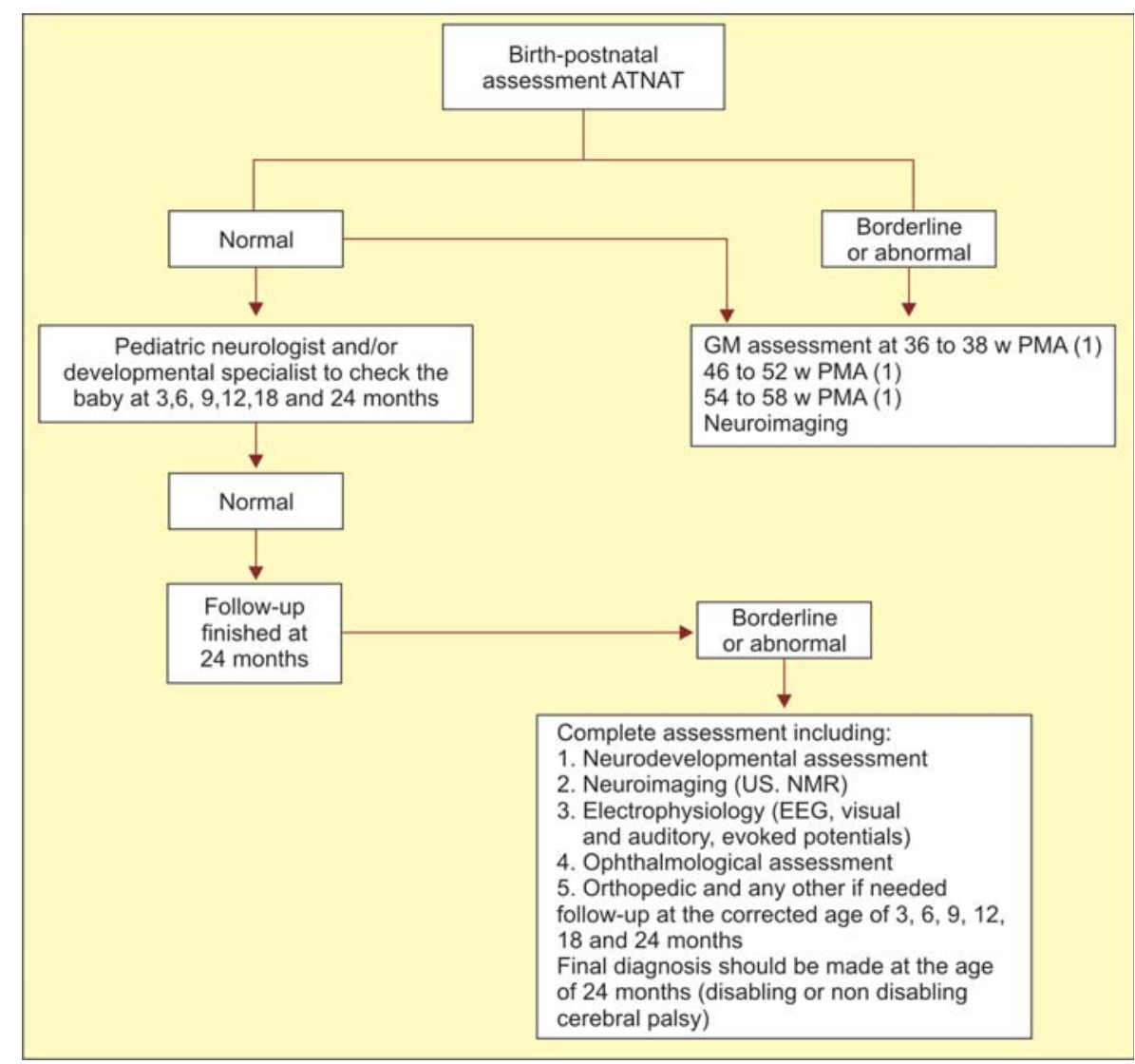

Figure 4: Postnatal assessment Flow Chart

The primary outcome was the usefulness of KANET to identify the fetuses from high-risk pregnancies at neurological risk. Due to relatively small sample size statistical analysis is at the moment not possible.

The number of fetuses assessed in four centers with the results of the KANET score are given in Table 4, while outcome of fetuses after KANET assessment is presented in Table 5. Combined results from the KANET, ATNAT and general movement of the survivors is presented in Table 6.

As shown in Table 6, a total of 7 fetuses had abnormal KANET scores, and 25 fetuses were borderline, for 32 fetuses at neurological risk. Of the 7 fetuses with an abnormal KANET, postnatal neurological assessment by Amiel Tison's method (ATNAT) revealed 3 newborns (arthrogryposis, vermis aplasia and neonate of the mother with the previous child with CP) out of 7 fetuses to be abnormal, while 4 were considered normal (ventriculomegaly, pre-eclampsia, thrombophylia, oligohydramnios). Out of the 25 borderline KANET fetuses there were 22 borderline newborns by ATNAT, while 3 were normal (ventriculomegaly, syndrome of intraamniotic infection,
Table 4: The number of fetuses assessed in four centers with the results of the KANET score

\begin{tabular}{|c|c|c|c|c|}
\hline \multirow[t]{2}{*}{ Center } & \multirow[t]{2}{*}{$\begin{array}{l}\text { Number of } \\
\text { fetuses }\end{array}$} & \multicolumn{3}{|c|}{$\begin{array}{l}\text { Prenatal neurological assessment } \\
\text { (KANET) }\end{array}$} \\
\hline & & Normal & Borderline & Abnormal \\
\hline Doha & 58 & 39 & 11 & 8 \\
\hline Bucharest & 68 & 62 & 5 & 1 \\
\hline Istanbul & 45 & 34 & 5 & 6 \\
\hline Zagreb & 117 & 105 & 9 & 3 \\
\hline Total & 288 & 240 & 30 & 18 \\
\hline
\end{tabular}

KANET $=$ Kurjak antenatal neurodevelopmental test.

Table 5: Outcome of fetuses after KANET assessment

\begin{tabular}{|c|c|c|c|c|}
\hline KANET score & Terminated & Died & Alive & Total \\
\hline $0-5$ & 5 & 6 & 7 & 18 \\
\hline $6-13$ & 2 & 3 & 25 & 30 \\
\hline$\geq 14$ & 6 & 0 & 234 & 240 \\
\hline Total & 13 & 9 & 266 & 288 \\
\hline
\end{tabular}

KANET $=$ Kurjak antenatal neurodevelopmental test. 
Table 6: Combined results from the KANET, ATNAT and general movement assessment

\begin{tabular}{|c|c|c|c|c|c|c|}
\hline \multicolumn{2}{|c|}{$\begin{array}{l}\text { Results of postnatal } \\
\text { general movements (GMs) }\end{array}$} & \multicolumn{3}{|c|}{$\begin{array}{l}\text { Postnatal neonatal neurological } \\
\text { assessment (ATNAT) }\end{array}$} & \multicolumn{2}{|c|}{ Prenatal assessment (KANET) } \\
\hline & & Normal & Borderline & Abnormal & Borderline & Abnormal \\
\hline Normal optimal & 4 & 3 & 1 & 0 & 4 & 0 \\
\hline Normal suboptimal & 20 & 4 & 16 & 0 & 20 & 0 \\
\hline Abnormal & 6 & 0 & 5 & 1 & 1 & 5 \\
\hline Definitely abnormal & 2 & 0 & 0 & 2 & 0 & 2 \\
\hline Total & 32 & 7 & 22 & 3 & 25 & 7 \\
\hline
\end{tabular}

KANET $=$ Kurjak antenatal neurodevelopmental test, ATNAT $=$ Amiel-Tison's neurological assessment at term

maternal thrombocytopenia). Those who were abnormal prenatally and normal postnatally had following prenatal risk factors: ventriculomegaly, Dandy Walker syndrome, skeletal dysplasia, polihydramnios, hydrocephaly, diabetes in pregnancy, nonimmune hydrops, syndrome of intra-amniotic infection, IUGR, trisomy 21, thrombocytopenia, thrombophylia, pre-eclampsia, achondroplasia, oligohydramnios. Out of the three abnormal neonates after ATNAT assessment, 2 had definitely abnormal Prechtl's premature general movements (arthrogryposis and vermis aplasia), and additional 6 were considered abnormal (neonate of the mother with the previous child with CP, Dandy Walker syndrome, hydrocephaly, trisomy 21, ventriculomegaly, nonimmune hydrops). Rest of 24 children had normal optimal or normal suboptimal GMs.

\section{DISCUSSION}

Despite medical reports from 100 years ago and 25 years of systematic research initiated by Prechtl and deVries the study of fetal neurobehavior is still in its infancy. There were attempts to develop a prenatal neurological screening test based on two dimensional ultrasound. The test was based on quantifying the fetal movements and did not take into account the quality and variability of the movements. The facial expressions were not included in these tests since they can only be clearly visualized by 4D ultrasound. The duration of the test was from 30 to 60 minutes and was not practical for daily use. The most comprehensive review article on fetal behavior included 109 papers, the authors conclusion was that the future studies of fetal behavior have to focus on spontaneous fetal movements and general movements. It was stressed that the new 4D ultrasound technology could be the tool enabling new insight into fetal neurobehavior. The implementation of this new diagnostic data has raised our knowledge about central nervous system development. Furthermore, the traditional concept that the brain damage is caused during birth or early neonatal period has been challenged, antenatal and unclassifiable factors are now considered as most important etiological factors.

The three illustrative cases with abnormal KANET scoring that we would like to present are arthrogryposis, vermis aplasia, and fetus whose previous sibling had verified $\mathrm{CP}$. The fetuses in these three cases had especially reduced facial movements, the faces were like mask during repeated scans. Fetuses with vermis aplasia and arthrogryposis had normal cranial sutures but the isolated head flexion was small in range for both cases. Isolated hand movements, hand to face and leg movements were poor in repertoire for all three cases. The finger movements were cramped and invariable in all three cases. The Gestalt perception of General movements was abnormal in all three cases. We also followed longitudinally the behavior of a fetus with acranius. The mother decided not to terminate the pregnancy due to religious reasons. It has been clearly documented that the fetus at 20 weeks of gestation had hypertonic movements with high amplitude and high speed. The movements emerged abruptly with burst-paused patterns, the variability of head movements was missing, without changes of facial expressions. As the gestational age advanced and the motor control was shifting from lower to upper control center the movement patterns changed as well. At the gestational age of 32 weeks the fetus had no facial expressions (face as a mask) and hand movement repertoire was very poor. At 36 weeks the absence of both the facial expressions and limb movements was observed. The neonate died during labor.

It seems that some of the prenatal conditions are temporarily affecting fetal neurological status (ventriculomegaly, SIAI, thrombocytopenia, thrombophylia, 
polihydramnios, pre-eclampsia,IUGR, achondroplasia), having tendency for improvement in neurological status after birth. On the basis of our preliminary results, we can only speculate why this happened after delivery. It is known that birthing process is affecting neonates neurologically, but it seems like some fetuses got liberated after birth due to numerous intrauterine constrains.

Our study shows that the new test might be useful in standardization of neurobehavioral assessments. Furthermore there is a potential for antenatal detection of serious neurological problems. At this stage test easily separates serious structural anomalies associated with brain impairment (artrhoghryposis, vermis aplasia, anencephaly). Most of the high-risk cases have been found with normal neurobehavior and that has been proven by experienced neonatologist. Understandable serious abnormalities with brain impairment and abnormal test have been detected earlier and terminated.

This is work in progress and four collaborating centers are continuing investigation. In some of the centers (Doha, Zagreb) preliminary results are already obtained after one year of life. It is our belief that the new test is a promising tool for the assessment of integrity of young central nervous system. However, the test requires further studies before being recommended for wider clinical practice. In the meantime the potential of antenatal scoring system should not be neither overestimated nor underestimated.

\section{CONCLUSION}

One of the most promising advances in the unknown field of prenatal behavior has been the new 3D/4D-US technology. Its advance has been completed in giving visualizations in almost real-time and production of standards for different movement patterns to appear and develop. The 4D study of fetal behavior provided us with a great possibility of understanding the hidden function of the developmental pathway of the fetal CNS and the potentialities of originating a neurological investigation in utero. By 4D technology we might be able to visualize an intrauterine neurological condition that would enable to identify which fetus is at risk and which is not. Existence of motoric competence in the newborn, even preterm infants is assumed to have its origins in prenatal life. Behavioral perinatology assessed by 4D sonography should be an interdisciplinary area of research involving concepts and conducting studies of the dynamic interplay between behavioral processes in fetal, neonatal, and infant life. The ultimate clinical application of fetal neurobehavioral assessment will be to identify functional characteristics of the fetus that predict a range of subsequent developmental dysfunction. Establishing this link will require demonstration of positive and negative predictability to outcomes significantly beyond the immediate perinatal period. After standardization of valid reference ranges of movements appropriate for the gestational age, attempts have been made to produce a new scoring system for fetal neurobehavior based on prenatal assessment by 3D/4D sonography. That preliminary work may help in detecting fetal brain and neurodevelopmental alterations due to in utero brain impairment that is inaccessible by any other method.

\section{REFERENCES}

1. Prechtl HFR. Qualitative changes of spontaneous movements in fetus and preterm infant are a marker of neurological dysfunction. Early Hum Dev 1990;23:151-58.

2. Nijhuis JG (Ed). Fetal behaviour: Developmental and perinatal aspects. Oxford: Oxford University Press, 1992.

3. Lee A. Four-dimensional ultrasound in prenatal diagnosis: Leading edge in imaging technology. Ultrasound Rev Obstet Gynecol 2001;1:194-98.

4. Kozuma S, Baba K, Okai T, Taketani Y. Dynamic observation of the fetal face by three-dimensional ultrasound. Ultrasound Obstet Gynecol 1999;13:283-84.

5. Campbell S. 4D or not 4D: That is the question. Ultrasound Obstet Gynecol 2002;19:1-4.

6. Azumendi G, Kurjak A. Three-dimensional and four-dimensional sonography in the study of the fetal face. Ultrasound Rev Obstet Gynecol 2003;3:1-10.

7. Kurjak A, Carrera J, Medic M, Azumendi G, Andonotopo W, Stanojevic M. The antenatal development of fetal behavioral patterns assessed by four-dimensional sonography. J Matern Fetal Neonatal Med. 2005;17:401-16.

8. Kurjak A, Pooh RK, Merce LT, Carrera JM, Salihagic-Kadic A, Andonotopo W. Structural and functional early human development assessed by three-dimensional and fourdimensional sonography. Fertil Steril 2005;84(5):1285-99.

9. de Vries JIP, Visser GH, Prechtl HF. The emergence of fetal behavior, I. Qualitative aspect. Early Hum Dev 1982;7:301-22 Oxford: Oxford University Press.

10. de Vries JIP, Visser GHA, Prechtl HFR. The emergence of fetal behaviour, II. Quantitative aspects. Early Hum Dev 1985;12: 99-120.

11. Andonotopo W, A Kurjak, MI Kosuta. Behavioral of anencephalic fetus studied by 4D sonography. J Matern Fetal Neonatal Med 2005;17:165.

12. Andonotopo W, Stanojevic M, Kurjak A, Azumendi G, Carrera JM. Assessment of fetal behavior and general movements by four-dimensional sonography. Ultrasound Rev Obstet Gynecol 2004;4:103.

13. Kurjak A, Kupesic S, Banovic I, Hafner T, Kos M. The study of morphology and circulation of early embryo by three-dimensional ultrasound and Power Doppler. J Perinat Med 1999;27:145. 
14. Kurjak A, Carrera JM, Andonotopo W, Azumendi G, Medic M, Salihagic-Kadic A. Behavioral perinatology assessed by fourdimensional sonography. In: Textbook of perinatal medicine, Kurjak A, ed. Jaypee Brothers Medical Publishers, New Delhi.

15. Kurjak A, Vecek N, Hafner T, Bozek T, Funduk-Kurjak B, Ujevic B. Prenatal diagnosis: What does four-dimensional ultrasound add? J Perinat Med 2002;30:57-62.

16. Kurjak A, Carrera JM, Stanojevic M, Andonotopo W, Azumendi G, Scazzocchio E, Medic M, Salihagic-Kadic A. The role of 4D sonography in the neurological assessment of early human development. Ultrasound Rev Obstet Gynecol 2004;4:148-59.

17. Andonotopo W, Medic M, Salihagic-Kadic A, Milenkovic D, Maiz N, Scazzocchio E. The assessment of fetal behavior in early pregnancy: Comparison between 2D and 4D sonographic scanning. J Perinat Med 2005;33:406-14.

18. Pooh RK, Ogura T. Normal and abnormal fetal hand position and movement in early pregnancy detected by three- and fourdimensional ultrasound. Ultrasound Rev Obstet Gynecol 2004;4:46.

19. Yigiter AB, Kavak ZN. Normal standards of fetal behavior assessed by four-dimensional sonography. J Matern Fetal Neonatal Med 2006;19(11):707-21.

20. Kuno A, Akiyama M, Yamashiro C, Tanaka H, Yanagihara T, Hata T. Three-dimensional sonographic assessment of fetal behavior in the early second trimester of pregnancy. J Ultrasound Med 2001;20:1271-75.

21. Sparling JW, Van To! J, Chescheir NC. Fetal and neonatal hand movement. Phys Ther 1999;79:24-39.

22. Roodenburg PJ, Wladimiroff JW, van Es A, Prechtl HF. Classification and quantitative aspects of fetal movements during the second half of normal pregnancy. Early Hum Dev 1991;25: 19-35.

23. Kurjak A, Azumendi G, Vecek N, et al. Fetal hand movements and facial expression in normal pregnancy studied by fourdimensional sonography. J Perinat Med 2003;31(6):496.

24. Kurjak A, Stanojevic M, Andonotopo W, Scazzocchio-Duenas E, Azumendi G, Carrera JM. Fetal behavior assessed in all three trimesters of normal pregnancy by four-dimensional ultrasonography. Croat Med J 2005;46:772-80.

25. Kurjak A, Andonotopo W, Hafner T, Salihagic Kadic A, Stanojevic M, Azumendi G, Ahmed B, Carrera JM, Troyano JM. Normal standards for fetal neurobehavioral developments: Longitudinal quantification by four-dimensional sonography. $\mathrm{J}$ Perinat Med 2006;34:56-65.
26. Prechtl HFR, Fargel JW, Weinmann HM, Bakker HH. Postures, motility and respiration of low-risk preterm infants. Dev Med Child Neurol 1979;21:3-27.

27. Nijhuis JG, Prechtl HF, Martin CB Jr, et al. Are there behavioural states in the human fetus? Early Hum Dev 1982;6:177-95.

28. Prechtl HFR, Weinmann HM, Akiyama Y. Organization of physiological parameters in normal and neurologically abnormal infants. Neuropaediatric 1969;1:101-29.

29. de Vries JIP, Visser GH, Prechtl HF. The emergence of fetal behavior, I. Qualitative aspect. Early Hum Dev 1982;7:301-22 Oxford: Oxford University Press.

30. Kurjak A, Azumendi G, Andonotopo W, Salihagic-Kadic A. Three- and four-dimensional ultrasonography for the structural and functional evaluation of the fetal face. Am J Obstet Gynecol. 2007;196:16-28.

31. Kurjak A, Stanojevic M, Azumendi G, Carrera JM. The potential of four-dimensional (4D) ultrasonography in the assessment of fetal awareness. J Perinat Med 2005;33:46-53.

32. De Meyer V, W Zemen, CG Palmer: The face predicts the brain: Diagnostic significance of medial facial anomalies for holoprosencephaly (arhinencephaly). Pediatrics 1964;34:256.

33. Yan F, Dai SY, Akther N, Kuno A, Yanagihara T, Hata T. Fourdimensional sonographic assessment of fetal facial expression early in the third trimester. Int J Gynaecol Obstet. 2006;94: 108-13.

34. Kurjak A, Miskovic B, Stanojevic M, Amiel-Tison C, Ahmed B, Azumendi G, Vasilj O, Andonotopo W, Turudic T, SalihagicKadic A. New scoring system for fetal neurobehavior assessed by three- and four-dimensional sonography. J Perinat Med. 2008;36(1):73-81.

35. Amiel-Tison C. Neurological assessment of the neonate revisited: A personal view. Dev Med Child Neurol. 1990;32:1105-13.

36. Amiel-Tison C, Gosselin J, Kurjak A. Neurosonography in the second half of fetal life: A neonatologist's point of view. J Perinat Med 2006;34:437-46.

37. DiPietro JA, Costigan KA, Pressman EK. Fetal state concordance predicts infant state regulation. Early Hum Dev 2002;68:1-13.

38. Kurjak A, Abo-Yaqoub S, Stanojevic M, Basgul Yigiter A, Vasilj O, Lebit D, Naim Shaddad A, Ahmed B, Nese Kavak Z, Miskovic B, Vladareanu R, Spalldi Barisic L, Azumendi G, Younis M, Pooh RK, Salihagic Kadic A. The potential of 4D sonography in the assessment of fetal neurobehavior-multicentric study in high-risk pregnancies. J Perinat Med 2010;38:77-82. 